\title{
Condições de Trabalho e Saúde de trabalhadores em um restaurante universitário
}

\section{Working conditions and health of workers in a university restaurant}

\section{Condiciones de trabajo y salud de los trabajadores en un restaurante universitario}

\author{
Marina Greghi Sticca* \\ Universidade de São Paulo - USP, Ribeirão Preto, São Paulo, Brasil \\ Marina Bernardo Mandarini** \\ Universidade de São Paulo - USP, Ribeirão Preto, São Paulo, Brasil \\ Flavia Helen Moreira da Silva*** \\ Universidade de São Paulo - USP, Ribeirão Preto, São Paulo, Brasil
}

\begin{abstract}
RESUMO
O artigo trata de uma investigação realizada em um restaurante universitário, visando identificar relações entre as condições de trabalho e a saúde dos trabalhadores, a partir do referencial teórico e metodológico da ergonomia da atividade. A pesquisa, de natureza qualitativa, apontou a presença de fatores de risco ergonômicos e psicossociais relacionados às exigências da atividade, a carga de trabalho elevada, às dificuldades nas relações socioprofissionais e a forma como as tarefas eram distribuídas. A presença de doenças físicas foi apontada pelos entrevistados como uma das principais repercussões da atividade. As condições contratuais e de gestão também foram apontadas como fatores que afetavam a atividade dos entrevistados. Esses achados corroboram os dados já apresentados pela literatura e evidenciam a importância de um diagnóstico organizacional com foco na saúde do trabalhador que considere o trabalho em todos os seus componentes: condições físicas, contratuais, os processos e características da atividade e as condições sociogerenciais.
\end{abstract}

Palavras-chave: condições de trabalho, saúde, ergonomia.

\begin{abstract}
The article addresses an investigation carried out in a university restaurant, aiming to identify relationships between working conditions and workers' health, based on the Activity Ergonomics theoretical and methodological framework. The qualitative research showed the presence of ergonomic and psychosocial risk factors related to the demands of the activity, the high workload, the difficulties in the socio-professional relations and the tasks distribution. The presence of physical illnesses was pointed out by the interviewees as one of the main repercussions of the activity. Contractual
\end{abstract}


and management conditions were also identified as factors that affected the activity of the interviewees. These findings corroborate the data already presented in the literature and show the importance of an organizational diagnosis focused on workers' health that considers work in all its components: physical, contractual conditions, processes and characteristics of the activity and socio-political conditions.

Keywords: working conditions, health, ergonomics.

\begin{abstract}
RESUMEN
El artículo trata de una investigación realizada en un restaurante universitario, buscando identificar relaciones entre las condiciones de trabajo y la salud de los trabajadores, a partir del referencial teórico y metodológico de la ergonomía de la actividad. La investigación, de naturaleza cualitativa, apuntó la presencia de factores de riesgo ergonómicos y psicosociales relacionados con las exigencias de la actividad, la carga de trabajo elevada, las dificultades en las relaciones socioprofesionales y la forma en que las tareas eran distribuidas. La presencia de enfermedades físicas fue señalada por los entrevistados como una de las principales repercusiones de la actividad. Las condiciones contractuales y de gestión también fueron apuntadas como factores que afecta la actividad de los entrevistados. Estos hallazgos corroboran los datos ya presentados por la literatura y evidencian la importancia de un diagnóstico organizacional con foco en la salud del trabajador que considere el trabajo en todos sus componentes: condiciones físicas, contractuales, los procesos y características de la actividad y las condiciones sociogenerativas.
\end{abstract}

Palabras clave: condiciones de trabajo, salud, ergonomía.

O artigo trata de uma investigação realizada em um restaurante universitário de uma universidade pública que teve como objetivo identificar relações entre as condições de trabalho e a saúde dos trabalhadores. Fundamentada no referencial teórico e metodológico da ergonomia da atividade, buscou ao utilizar a Análise Ergonômica do Trabalho, analisar de forma aprofundada a atividade de trabalho dos profissionais.

As condições de trabalho representam um fenômeno complexo, relacionam-se ao trabalho e aos elementos que se situam em torno dele, e impactam diretamente a saúde, qualidade de vida e bemestar psicológico dos trabalhadores (Silva \& Borges, 2015). Segundo Borges, Costa, Alves-Filho e Falcão (2015), as condições de trabalho podem ser categorizadas em condições físicas e materiais, referentes ao espaço geográfico e arquitetônico e às instalações, condições contratuais e jurídicas, referentes aos aspectos que tipificam 0 trabalho quanto a sua natureza jurídica, processos e características da atividade, relacionados ao conteúdo, organização e execução das atividades, e, por fim, condições do ambiente sócio-gerencial, referentes às interações interpessoais e práticas de gestão.

As dimensões que compõem as condições de trabalho podem indicar a complexidade do lócus organizacional, sendo configuradoras das fontes do "Custo Humano do Trabalho", entendido como o custo 
despendido pelos trabalhadores nas esferas, física, cognitiva e afetiva, diante das contradições existentes no contexto de produção. As exigências que integram a noção de custo humano do trabalho são impostas pelas características do ambiente de trabalho (Ferreira \& Mendes, 2003).

Tais condições e contradições podem apresentar riscos à saúde dos trabalhadores. Os fatores de risco ocupacionais podem ser de vários tipos: físicos, químicos, biológicos, ergonômicos e psicossociais. Para Guimarães (2006), os fatores de risco psicossociais do trabalho (FRPT) são definidos como aquelas características do trabalho que funcionam como estressores, que implicam em exigências do posto de trabalho, combinadas com recursos insuficientes internos do trabalhador para o seu enfrentamento.

Estudos nacionais identificaram fatores de risco ligados ao cotidiano do trabalho em restaurantes e cozinhas industriais (Carvalho, 2008; Casarotto \& Mendes, 2003; Jorge et al., 2009; Monteiro, Ramos, Ribeiro, \& Garcia, 2014). O trabalho é dificultado pela existência de condições de trabalho adversas aos trabalhadores, como ruído excessivo, (Casarotto \& Mendes, 2003; Green \& Anthony, 2015; Jorge et al., 2009), instrumentos mal planejados que exigem a adoção de posturas inadequadas (Casarotto \& Mendes, 2003; Monteiro et al., 2014), realização de movimentos repetitivos e esforço físico excessivo (Carvalho, 2008).

Os estudos encontrados na revisão da literatura mostram adoecimento ocupacional que acomete trabalhadores neste setor da indústria no Brasil, sendo que tal realidade também é verificada em estudos internacionais. Subramanian e Murugesan (2015) identificaram a prevalência de $67 \%$ de ocorrência de distúrbios músculo-esqueléticos em trabalhadores de cozinha industriais; Haukka et al. (2011) investigaram a relação entre o estresse mental e fatores psicossociais no trabalho (controle do trabalho, discernimento de habilidade, suporte gerencial, relações interpessoais no trabalho e pressão temporal) e a predição de dores musculoesquelética entre mulheres que trabalham em cozinhas; Haruyama et al. (2014) encontraram correlação entre a ocorrência de queimaduras e cortes relacionados ao trabalho na cozinha com os níveis de estresse no trabalho entre cozinheiros industriais.

A revisão da literatura nacional e internacional apontou a existência de estudos em restaurantes universitários, sendo que a maioria dedica-se apenas à identificação das condições físicas e seus efeitos na saúde dos funcionários. Apenas um estudo investigou a relação entre fatores relacionados à organização do trabalho e seus efeitos na saúde do trabalhador (Haukka et al., 2011), e não foi encontrada nenhuma pesquisa que investigou todas as condições de trabalho de forma ampliada. 


\section{A perspectiva da Ergonomia da Atividade para o estudo das condições de trabalho e saúde do trabalhador}

O objetivo da ergonomia é observar e entender de forma mais ampla possível, por meio da análise das situações reais de trabalho, os comportamentos e seus significados para então transformar 0 trabalho e apreender da situação como o homem efetivamente se comporta para desempenhar a atividade (Guérin, Laville, Daniellou, Duraffourg, \& Kerguelen, 2001). A atividade de trabalho tem resultados sobre as pessoas, sua saúde e integridade física, e sobre a produção, podendo ser avaliada a qualidade dos produtos e da produtividade do trabalho (Pizo \& Menegon, 2010).

Segundo Falzon (2007), a ergonomia refere-se a uma transformação não apenas das situações de trabalho, mas também dos dispositivos, por meio da construção de conhecimentos do ser humano em atividade. Tal conhecimento é construído a partir do diálogo entre o trabalhador e o ergonomista, e do confronto de seus pontos de vista e tipos de conhecimentos. Neste sentido, a atividade de trabalho não é um objeto pronto, mas um objeto a ser constituído e reconstruído em comum. Para este autor, ao utilizar o termo "atividade de trabalho" a ergonomia refere-se ao trabalhador como um agente inteligente, com uma série de habilidades e conhecimentos práticos, baseado em suas experiências no trabalho, que o capacitam a controlar, regular, coordenar, e construir sua ação para alcançar determinado objetivo. Tal atividade é situada em um determinado contexto, composto por componentes materiais, sociais e históricos, que fornecem recursos, mas, também, apresentam constrangimentos. Simultaneamente, tal contexto é afetado pela experiência de vida subjetiva do trabalhador, que é constantemente revisada e atualizada.

Para compreender o trabalho, a análise da atividade utiliza a Análise Ergonômica do Trabalho (AET), que tem como fio condutor a atividade de trabalho e a busca pelo entendimento das ações humanas situadas em determinado contexto. A AET procura identificar determinantes de cada atividade, por meio da análise dos objetivos estabelecidos pela pessoa; características dos materiais e das ferramentas utilizadas; características próprias das pessoas e do contexto de uso. O objetivo da AET é compreender o trabalho real e confrontá-lo com o trabalho prescrito por meio da análise do trabalho e das atividades realizadas pelos trabalhadores nas situações de trabalho, e ordená-las em seus componentes físicos, cognitivos e emocionais, fornecendo subsídios para possibilidades de melhorias das condições de trabalho (Falzon, 2007; Ferreira, 2015).

A distância entre a tarefa prescrita e a atividade real de trabalho é, justamente, a lacuna que interessa à análise ergonômica para compreender como o homem relaciona-se com a tarefa. Interessa, 
nesse sentido, conhecer as estratégias operatórias adotadas pelos trabalhadores e a regulação realizada por eles durante a realização de uma atividade ocupacional. Tal informação é necessária para a compreensão de como ocorre a mobilização dos saberes durante o desenvolvimento da atividade, tratados na ergonomia como modos operatórios, definidos como um conjunto de ações que os sujeitos adotam em função das exigências da tarefa e de sua competência. É possível inferir que a construção do modo operatório adotado pelos trabalhadores é o resultado dos objetivos exigidos, dos meios de trabalho, dos resultados produzidos e de seu estado interno (Camarotto, Simonelli, \& Rodrigues, 2013).

Sendo assim, para compreender as condições de trabalho e a saúde do trabalhador é necessário identificar dentre os diferentes elementos que compõem a atividade, aqueles elementos fundamentais, os quais determinam a carga de trabalho (Guérin, Laville, Daniellou, Duraffourg \&, Kerguelen, 2001). O adoecimento surge em situações em que não é possível agir sobre os meios e objetivos da tarefa, então o trabalhador tenta atingir os resultados a custo de modificação do estado interno, suscetíveis de se traduzirem, com o tempo, em agressões à saúde (Falzon, 2007). De acordo com os objetivos desta pesquisa, identificar relações entre as condições de trabalho e a saúde dos trabalhadores, a partir de uma abordagem do trabalho em todas as suas dimensões, a AET aparece como um importante aporte teórico que contribui para a compreensão das relações entre as condições físicas, contratuais, os processos e características da atividade e as condições sociogerenciais e seus impactos na saúde do trabalhador.

\section{Método}

Este estudo exploratório, de natureza qualitativa, utiliza-se de pressupostos teóricos da ergonomia da atividade, tendo como abordagem metodológica a análise ergonômica do trabalho ( $A E T)$, conforme pressupostos propostos por Guérin et al. (2001). A AET é uma abordagem de análise do trabalho e da atividade que privilegia a relação entre as condições de execução do trabalho e as atividades desenvolvidas pelos trabalhadores em seus componentes físicos, cognitivos e emocionais, feita em campo, ou seja, baseada no trabalho realizado pelos trabalhadores nas situações de trabalho, fornecendo subsídios para possibilidades de melhorias das condições de trabalho. 


\section{Contexto do estudo: o restaurante universitário}

A coleta de dados ocorreu no período de agosto a outubro de 2016, em um restaurante universitário de uma universidade pública do estado de São Paulo. No período referente à coleta, o restaurante existia há mais de 40 anos, era responsável por fornecer café da manhã, almoço e jantar aos alunos e visitantes autorizados da Universidade. O restaurante produzia cerca de 1600 refeições diárias. O restaurante possuía 39 funcionários, sendo que 5 constituíam a equipe técnica, composta por duas nutricionistas, duas técnicas em nutrição e uma assistente administrativa, um tinha a função de zelador e 33 eram responsáveis pela produção e reposição das refeições.

\section{Participantes}

As características dos participantes estão sumarizadas na Tabela 1. Participaram do estudo 28 funcionários concursados da equipe técnica e operacional do restaurante que ocupam funções relacionadas ao preparo, reposição dos alimentos e às funções administrativas e de zelador. Também participou do estudo a chefe da equipe técnica, contribuindo com informações referentes a análise das tarefas, organização e condições de trabalho. De acordo com a Tabela 1, observa-se que $75 \%$ dos funcionários possuem acima de 50 anos e $39 \%$ trabalham há mais de 20 anos no restaurante.

\begin{tabular}{lccc}
$\begin{array}{l}\text { Tabela } 1 \\
\text { Descrição das Características dos Participantes }\end{array}$ & & \\
\hline Características & Categorias & $\begin{array}{c}\text { Número de } \\
\text { participantes }\end{array}$ & $\begin{array}{c}\text { Porcentagem } \\
(\%)\end{array}$ \\
Idade & Maior que 60 anos & 6 & $21 \%$ \\
& $\begin{array}{l}\text { Entre } 50 \text { e } 60 \text { anos } \\
\text { Menor que } 50 \text { anos }\end{array}$ & 15 & $54 \%$ \\
Sexo & Mulheres & 17 & $25 \%$ \\
\multirow{2}{*}{ Função } & Homens & 11 & $61 \%$ \\
& Auxiliar de cozinha & 11 & $39 \%$ \\
Tempo de trabalho & Cozinheiro & 17 & $39 \%$ \\
& Mais de 20 anos & 11 & $61 \%$ \\
\hline
\end{tabular}




\section{Procedimentos}

Para atender ao objetivo do estudo, foram realizadas cinco etapas de procedimentos, de acordo com Abrahão, Sznelwar, Silvino, Sarmet e Pinho (2009): 1. Análise da Demanda; 2. Análise Organizacional; 3. Análise das Tarefas; 4. Análise das Atividades; e 5. Validação.

A primeira etapa teve o objetivo de compreender a natureza das questões e problemas existentes na organização. A demanda identificada foi a necessidade de analisar as condições de trabalho da equipe de produção, a fim de verificar a viabilidade de continuar as operações com a equipe disponível no restaurante.

A segunda etapa, análise organizacional, consistiu no levantamento de informações sobre a organização e sua articulação com a demanda. Para tanto, foi realizada uma entrevista semiestruturada com a chefe da equipe técnica, a fim de levantar informações sobre a organização, e uma análise documental, com o objetivo de coletar dados acerca do processo de produção, organização e condições de trabalho e estado de saúde dos trabalhadores (índices de afastamento e descrição das restrições médicas da equipe operacional).

A etapa da análise das tarefas teve o objetivo de caracterizar o processo de produção, bem como identificar as condições e organização do trabalho (natureza da tarefa, controle, constrangimento temporal, hierarquia, entre outros) a que estavam submetidos os trabalhadores. Nesta etapa foram realizadas observações globais e abertas das atividades realizadas no restaurante universitário, com o objetivo de elaborar um prédiagnóstico. Também foram realizadas entrevistas semiestruturadas com 28 funcionários do setor operacional.

A análise das atividades e situações de trabalho visou caracterizar as atividades reais realizadas pelos trabalhadores. Foram realizadas observações sistemáticas de postos de trabalho que foram identificados no pré-diagnóstico como sendo de maior risco para a saúde dos trabalhadores, entrevistas semiestruturadas com os mesmos 28 funcionários e aplicação de instrumento Índice de Capacidade para o Trabalho (ICT). As entrevistas semiestruturadas foram realizadas individualmente com cada participante, juntamente com a aplicação do ICT. Por fim, as observações sistemáticas foram executadas ao longo de um dia inteiro de trabalho, durante um período de uma semana de trabalho.

A última etapa consistiu na validação individual e coletiva com os trabalhadores. Foi realizada uma reunião com os trabalhadores para apresentar os dados resultantes da pesquisa. Também foram realizadas conversas individuais para apresentar os dados coletados e verificar se estes retratavam de fato a percepção dos funcionários em relação a suas condições de trabalho. 


\section{Instrumentos}

Além dos roteiros de entrevista semiestrurados, foram utilizados, um roteiro de observação sistemática e o Índice de Capacidade para o Trabalho (ICT). O roteiro de entrevista utilizado com a chefe da equipe técnica foi elaborado com base na coleta de informações sobre a empresa, proposta pela AET (Abrahão et al., 2009), e teve o objetivo de levantar informações sobre a organização, como informações referentes ao organograma, processo de trabalho diário, organização das tarefas e divisão do trabalho. O roteiro de entrevista utilizado com os funcionários foi elaborado com o objetivo de levantar as características dos funcionários e acessar suas percepções em relação às condições físicas, organização das tarefas e divisão do trabalho.

O roteiro de observação foi elaborado a partir das premissas da análise ergonômica do trabalho, e teve como objetivo compreender o trabalho realizado, aferir o fluxo de processos e inter-relações, analisar os pontos de lentidão e as dificuldades para a realização do trabalho (Abrahão et al., 2009).

Por fim, o Índice de Capacidade para o Trabalho (ICT) (Tuomi, Ilmarinen, Jahkola, Katajarinne, \& Tulkki, 2005) tem como objetivo avaliar a relação entre estressores e a capacidade para o trabalho de profissionais de saúde (Gemma, Fuentes-Roja, \& Soares, 2017; Martinez, Latorre, \& Fischer, 2017). O instrumento tem índice de confiabilidade de 0,8 , e é composto por itens que avaliam a percepção dos trabalhadores em relação ao quão bem estão ou estarão, e quão bem podem executar seu trabalho em função das exigências, de seu estado de saúde e de suas capacidades físicas e mentais. A partir do escore, o sujeito é classificado quanto à sua capacidade para o trabalho em: baixa capacidade (7-27), moderada capacidade (28-36); boa capacidade (37-43) e ótima capacidade (4449) (Tuomi et al., 2005).

\section{Procedimentos de análise dos dados}

As entrevistas individuais e a entrevista com a chefe da equipe técnica foram gravadas e posteriormente transcritas integralmente. Nos procedimentos de análise documental e observação sistemática, as pesquisadoras utilizaram a técnica de registro cursivo das informações relevantes para o objetivo da pesquisa. As análises do material qualitativo foram realizadas utilizando-se o referencial da análise temática de nível semântico (Braun \& Clarke, 2006), de modo que as pesquisadoras identificaram, analisaram e relataram os padrões de temas presentes nos dados, a partir da análise temática dos dados qualitativos, sendo eles referentes à observação, às entrevistas individuais com os trabalhadores e com a chefia, e à 
análise documental. Foram criadas as seguintes categorias: saúde dos participantes, condições físicas e materiais, trabalho prescrito $x$ real e condições do ambiente sócio-gerencial.

\section{Cuidados Éticos}

Quanto aos cuidados éticos em pesquisa, este estudo foi aprovado pelo Comitê de Ética em Pesquisa da Faculdade de Filosofia, Ciências e Letras de Ribeirão Preto da Universidade de São Paulo, sob o protocolo no 39022514.0.0000.5407 conforme Resolução no 466/12 do Conselho Nacional de Saúde. Foi acordada a disposição de uma sala privativa para a realização das entrevistas com os funcionários, a liberação dos mesmos no período da coleta, bem como a autorização para a publicação dos resultados, garantindo o anonimato da organização e seus trabalhadores.

\section{Resultados}

\section{Saúde dos participantes}

Os resultados referentes a aplicação do Índice de Capacidade para o Trabalho (ICT) estão sumarizados na Tabela 2. Considerando as exigências do trabalho, seu próprio estado de saúde e suas capacidades físicas e mentais, metade dos participantes ( $n=14$; $50 \%$ ) percebeu uma capacidade boa para o trabalho. Onze participantes (39\%) apresentavam restrições físicas formais, decorrentes de avaliação médica, e três estavam temporariamente afastados de suas funções devido a problemas de saúde. A maioria dos entrevistados com restrição médica relatou que as condições e organização do trabalho eram responsáveis por seu adoecimento.

[...] Quando eu entrei aqui não tinha nada, não tinha colesterol alto. Tudo o que eu tenho hoje foi graças ao restaurante, à cozinha. Mas eu não posso culpar. Às vezes eu que não soube me adaptar, a me encaixar nessa vida de desespero que esse povo leva."

Em relação às restrições médicas, $62 \%$ dos funcionários relataram ter algum tipo de restrição na realização das atividades. Entre as restrições registradas, a maioria refere-se à elevação e transporte de peso, sendo que $25 \%$ dos participantes $(n=7)$ possuíam restrição com pesos maiores que $5 \mathrm{~kg}$ e $11 \%(n=3)$ possuíam restrição com pesos maiores que $10 \mathrm{~kg}$ (Tabela 2 ). Durante as entrevistas e após a aplicação do ICT, identificou-se que as lesões e dores na coluna foram as queixas de saúde citadas com maior frequência, seguidas 
Marina Greghi Sticca, Marina Bernardo Mandarini, Flavia Helen Moreira da Silva

pelas lesões e dores nos membros inferiores e superiores, e problemas ou diminuição da audição (Tabela 2).

Tabela 2

Classificação do ICT, Lesões ou Doenças Percebidas e Tipos de Restrição Física dos Participantes

\begin{tabular}{|c|c|c|}
\hline Classificação do ICT & $\begin{array}{l}\text { Número de } \\
\text { participantes }\end{array}$ & $\begin{array}{l}\text { Porcentagem } \\
\qquad(\%)\end{array}$ \\
\hline Capacidade ótima & 5 & $18 \%$ \\
\hline Capacidade boa & 14 & $50 \%$ \\
\hline Capacidade moderada & 7 & $25 \%$ \\
\hline Capacidade baixa & 2 & $7 \%$ \\
\hline \multicolumn{3}{|l|}{ Lesões ou doenças percebidas (ICT) } \\
\hline Lesões e dores nos membros superiores & 6 & $21 \%$ \\
\hline Lesões e dores nos membros inferiores & 7 & $25 \%$ \\
\hline Lesões e dores na coluna & 16 & $57 \%$ \\
\hline Problemas ou diminuição da audição & 5 & $18 \%$ \\
\hline \multicolumn{3}{|l|}{ Tipo de restrição física } \\
\hline Elevar e carregar pesos maiores que $5 \mathrm{~kg}$ & 7 & $25 \%$ \\
\hline Elevar e carregar pesos maiores que $10 \mathrm{~kg}$ & 3 & $11 \%$ \\
\hline Percorrer longas distâncias & 1 & $4 \%$ \\
\hline $\begin{array}{l}\text { Movimentação dos membros superiores } \\
\text { limitada }\end{array}$ & 1 & $4 \%$ \\
\hline $\begin{array}{l}\text { Realizar trabalhos em alturas elevadas, como } \\
\text { subir em escadas }\end{array}$ & 1 & $4 \%$ \\
\hline $\begin{array}{l}\text { Operar máquinas e instrumentos que podem } \\
\text { causar acidentes }\end{array}$ & 1 & $4 \%$ \\
\hline $\begin{array}{l}\text { Realização de atividades que exigem esforço } \\
\text { físico }\end{array}$ & 1 & $4 \%$ \\
\hline
\end{tabular}

\section{Condições físicas e materiais}

Foram constatadas condições físicas e materiais desfavoráveis à saúde dos funcionários. De acordo com as observações e os relatos dos participantes, foi possível identificar o restaurante como um ambiente com altos níveis de ruídos, proveniente principalmente do maquinário e manipulação dos utensílios, dos caminhões de transporte, que estacionavam e descarregavam os alimentos próximo ao restaurante, e da movimentação dos carrinhos de transporte de alimentos, dificultada pela qualidade do piso. Os relatos apontaram que o ruído interferia na realização das atividades, bem como afetava a saúde física e mental. 
"O barulho dessa cozinha tá quase me deixando louca da cabeça [...]. (Auxiliar de cozinha)

"eu saio daqui parece que a minha cabeça tá do tamanho de um elefante". (Auxiliar de cozinha)

Em relação aos equipamentos de proteção individual (EPI) auditivo, notou-se que, apesar da chefia disponibilizá-los, a maioria dos trabalhadores não utilizava o equipamento. Nas entrevistas verificouse que os trabalhadores alegaram que a utilização dificultava a realização das tarefas, como a comunicação com outros colegas, necessária durante a realização das atividades na cozinha. Verificouse que outros equipamentos de proteção, como as luvas térmicas utilizadas pelos cozinheiros, não eram apropriadas para a realização das atividades. As luvas eram curtas e deixavam parte do braço do trabalhador exposta a altas temperaturas ao manusear os fornos, oferecendo risco ao realizar esta tarefa. A exposição a variações de temperatura também foi identificada como condição física prejudicial, sendo que a exposição a temperaturas baixas nas câmaras frias e a constantes correntes de ar gelado por alguns auxiliares de cozinha, devido à proximidade entre a mesa de escolha dos grãos e as câmaras, foi relatada de forma negativa pelos trabalhadores.

Por fim, verificou-se a inadequação dos carrinhos de transporte de alimentos, das caixas de armazenamento das carnes e dos tambores de armazenamento de grãos. A altura dos carrinhos de transporte era menor que a altura média dos braços dos funcionários, as caixas de armazenamento das carnes eram posicionadas no chão e os tambores de armazenamento eram pesados e não possuíam rodinhas para facilitar o transporte dos mesmos. Devido a esses aspectos, os trabalhadores precisavam adotar posturas desconfortáveis e prejudiciais para a saúde para a realização dessas tarefas, como abaixar e levantar diversas vezes, manter uma postura inclinada e realizar intenso esforço físico.

Dos 28 participantes desta pesquisa, $16(57 \%)$ relataram a existência de lesões e dores na coluna. De acordo com a identificação da inadequação dos utensílios, que exigia a adoção de posturas e movimentos de risco, pode-se considerar este aspecto como uma das possíveis causas para o surgimento e intensificação das lesões em questão nos funcionários.

\section{Trabalho Prescrito x Real}

Verificou-se discrepâncias existentes entre as tarefas prescritas e a atividade real de trabalho. A partir das entrevistas foram constatadas contradições percebidas pelos funcionários ligadas às questões contratuais referentes à atribuição de nomenclaturas de cargos e 
suas respectivas descrições de funções e atividades, que culminavam na geração de tensão e conflitos. Tais contradições ocorriam devido a alterações que foram realizadas nas descrições de cargos dos cozinheiros, tendo sido efetuada a divisão das funções do cozinheiro entre os novos cargos de "auxiliar de cozinha" e de "cozinheiro". Dessa forma, os funcionários mais antigos haviam sido contratados como cozinheiros e aqueles contratados mais recentemente foram contratados sob a função de cozinheiros ou sob a função de auxiliares de cozinha.

Esta situação foi vista de forma negativa por alguns funcionários mais antigos que afirmaram que sua descrição de cargo incorporava mais funções do que a de um cozinheiro contratado após a alteração, porém realizando muito mais atividades do que aqueles que foram contratados apenas como cozinheiros, como exemplificado na fala do trabalhador.

"Então no perfil da minha função [...] eles incorporaram todos os trabalhos, todos os serviços que antes eram feitos pelos auxiliares de cozinha, então foi uma mascarada [...]. Porque eu aqui como cozinheiro I, eu faço tudo que o cozinheiro faz, tenho as mesmas responsabilidades [...] enquanto cozinheiro II não, cozinheiro II só fica na cocção. E eu faço as mesmas funções do que ele e ganho menos do que ele, ganho igual um auxiliar de cozinha." (Cozinheiro)

Este incômodo era intensificado pela avaliação de desempenho realizada pela equipe técnica do restaurante, que refletia no plano de carreira dos funcionários, determinando a mudança de nível de cargo e o aumento do salário e outras bonificações. Sendo assim, alguns funcionários afirmavam ganhar o mesmo que um auxiliar de cozinha e fazer todas as outras funções do cargo de cozinheiro estando no primeiro nível do plano de carreira.

As descrições de cargo também foram consideradas problemáticas uma vez que não definiam precisamente todas as atividades que deveriam ser desempenhadas, abrangendo também nos termos "funções correlatas" aquelas que não estavam listadas na descrição, mas que estavam relacionadas ao cotidiano do trabalho no restaurante. Esta situação na visão dos entrevistados gerava sobrecarga de trabalho e inúmeros conflitos entre a equipe de funcionários e entre estes e a chefia, que por sua vez estabelecia escalas de trabalho para a organização das tarefas e encontrava resistência de alguns funcionários que se recusavam a realizar alguns tipos de atividades por estas não se encontrarem no escopo de seu cargo. A questão das funções e escalas foi comentada por vários funcionários nas entrevistas, e as duas falas seguintes retrataram as dificuldades enfrentadas na gestão das escalas. 
"[...] e na questão de escalas também tem aquelas pessoas que não aceitam fazer certas coisas, então elas não vão pra certas escalas, outras porque o contrato é mais antigo e não obriga a fazer certas coisas e também não vão, e isso acaba sobrecarregando outras pessoas, que no caso nós que já vínhamos com contrato amplo que diz que a gente tem que fazer tudo, então a gente acaba sendo sobrecarregado mais." (Cozinheiro)

"A chefia pôs esse negócio de escala de serviço, e eu já sabia que não ia dar certo. O pessoal vai olhar a escala e vai querer fazer só aquilo ali. Deu certinho, foi justamente o que eles acharam. Então o serviço acumula." (Cozinheiro)

A partir da fala dos entrevistados verificou-se que alguns funcionários, por diversos motivos, não concordavam com algumas atribuições de tarefas dadas pela equipe técnica, que não encontrava respaldo no âmbito administrativo devido à falta de clareza das descrições de cargos encontradas nos contratos de trabalho. Sendo assim, aqueles funcionários com contratos que abrangiam mais funções acabavam por assumir tarefas que podiam não ser de sua responsabilidade direta, mas que estavam relacionadas às suas atividades de forma geral, gerando impactos tanto no cotidiano de trabalho quanto para a própria saúde do trabalhador que fica sobrecarregado.

\section{Condições do ambiente sociogerencial}

Foram relatadas dificuldades no relacionamento interpessoal entre a equipe da cozinha e entre a chefia, falta de diálogo e cooperação, constituindo fatores que contribuíam para a existência de conflitos que se desdobravam em insultos verbais, desavenças e sentimentos negativos por parte de alguns funcionários. De acordo com o relato de um dos funcionários, os obstáculos colocados pela falta de diálogo impactavam diretamente no trabalho e no processo de produção.

Foi constatado que não existia um tempo dedicado à comunicação entre os funcionários da cozinha e a equipe técnica e chefia, sendo que nenhum dos problemas ocorridos no cotidiano de trabalho eram comunicados e, consequentemente, não eram manejados pela equipe técnica e chefia com eficiência. Conflitos que surgiam devido às diversas condições anteriormente expostas impactavam na integração da equipe e no clima organizacional, e poderiam, inclusive, afetar o desempenho dos funcionários e seu bem-estar, como relatado por uma das funcionárias da cozinha. 
"Só que vai chegando uma hora [...] fica um clima muito difícil [...] comecei a perceber que não era só incômodo, que era perseguição de uma ou outra pessoa, e isso vai realmente detonando você. [...]"(Cozinheira)

"[...] na minha opinião a gente tá se gladiando aqui dentro faz tempo [...] a equipe não se entrosou, então que que aconteceu, ficaram os antigos de um lado e os novos de outro lado, e aí... não teve o entrosamento que precisava pra uma linha de produção. [...] porque aí a gente começou a sobrecarregar, e por sobrecarregar a gente começou a ter as restrições [...]" (Auxiliar de cozinha)

Os conflitos eram ainda mais intensos entre os grupos de funcionários mais novos e os mais antigos devido a incongruências nos processos produtivos, sendo que tais grupos trabalhavam de formas diferentes.

"[...] na minha opinião a gente tá se gladiando aqui dentro faz tempo. [...]" (Cozinheira)

"[...] a equipe não se entrosou, então que que aconteceu, ficaram os antigos de um lado e os novos de outro lado, e aí... não teve o entrosamento que precisava pra uma linha de produção [...]"'(Cozinheiro)

Este conflito por vezes era justificado pelos funcionários entrevistados por características dos editais de seleção referente às contratações mais recentes, que exigiam maiores níveis de escolaridade, resultando numa equipe de funcionários com níveis de instrução mais elevados. Desta forma, a formação acadêmica e experiência eram percebidas como incompatíveis com as exigências das tarefas, justificando a desmotivação daqueles funcionários com maior formação acadêmica, o que resultava em baixa identificação com as tarefas e menor cooperação com os outros trabalhadores.

"O pessoal que entrou, entrou com um grau de instrução diferente do pessoal que tava aqui. O fato deles terem um grau de instrução diferenciado, dificulta eles fazerem serviço braçal [...] E isso foi o que desmonta a equipe" (Cozinheiro)

"[...] porque eles têm outra visão, a visão deles foi mais pro estudo [...] de fazer curso, querem sair daqui pra ter [...] outro tipo de serviço, às vezes entraram na cozinha mas não é isso que gosta né $[\ldots]^{\prime \prime}$ (Cozinheiro) 


\section{Processos e características da atividade}

O trabalho no restaurante era organizado em escalas de trabalho, planejadas semanalmente com a finalidade de dividir as tarefas e realizar a rotação dos trabalhadores nas atividades, para evitar sua sobrecarga com apenas uma atividade. As escalas eram elaboradas de acordo com a disponibilidade física de cada funcionário, ou seja, levava-se em consideração a existência de restrições físicas. Desse modo, alguns funcionários não participavam de certas escalas devido a suas restrições.

Atualmente tá bem puxado, porque são poucas as pessoas que fazem o rodízio, por exemplo, puxar a carne no container, que a gente tem que carregar a caminhonete lá embaixo [...] açougue também [...] cê tem que abrir pacotinho por pacotinho de carne, então cê agacha, levanta, agacha, levanta (Cozinheira)

As atividades consideradas mais complexas eram atribuídas a funcionários com menos restrições. A disponibilidade limitada de funcionários para o cumprimento das escalas de trabalho acarretava a distribuição desigual de tarefas e a sobrecarga de atividades, sobretudo aquelas que exigiam intenso esforço físico. Tal divisão frequentemente resultava em conflitos entre os funcionários, pois alguns consideravam positiva a utilização de escalas de trabalho enquanto outros questionavam a imparcialidade da equipe técnica ao estruturá-la e ao supervisionar seu cumprimento, e julgavam como injusta tal divisão. Além disso, alguns comentaram que a utilização de escalas de trabalho contribuía para que não houvesse cooperação entre os funcionários na realização das atividades.

Essa organização da divisão do trabalho, em que aqueles que possuíam restrições físicas participavam das atividades que exigiam menor esforço físico e aqueles que não as possuíam acabavam responsáveis pelas atividades mais complexas e que demandavam maior esforço, gerava uma intensificação e sobrecarga de trabalho para aqueles que inicialmente não possuíam restrições e constituiu um fator de risco para o desenvolvimento de DORT e LER (Alencar, Cavalcanti, \& Montrezor, 2013; Brasil, 2012), estresse, síndromes depressivas e distúrbios de memória ou do pensamento (Falzon, 2009). Como $61 \%$ dos participantes não apresentava restrições físicas e participava da maioria das escalas de trabalho, considerouse que estes corriam o risco de desenvolver tais prejuízos à saúde, principalmente devido à sobrecarga de atividades. 


\section{Discussão}

Verificou-se que as principais lesões ou doenças apontadas pelos participantes foram lesões e dores nos membros superiores e inferiores, lesões e dores na coluna e problemas ou diminuição da audição. Estes resultados são semelhantes à prevalência de doenças ocupacionais dos trabalhadores de cozinhas da pesquisa realizada por Casarotto e Mendes (2003), em que os distúrbios osteomusculares relacionados ao trabalho (DORT) e as dores na coluna foram as doenças ocupacionais mais citadas pelos participantes. Também são semelhantes aos resultados encontrados por Subramaniam e Murugesan (2015) em estudo internacional. A existência de instrumentos anti-ergonômicos e que dificultam a realização da tarefa pelos trabalhadores foi ressaltada por Casarotto e Mendes (2003) e Monteiro et al. (2014), sendo fatores de risco para o surgimento de distúrbios osteomusculares (LER e DORT) (Alencar et al., 2013).

As lesões por esforços repetitivos (LER) e os distúrbios osteomusculares relacionados ao trabalho (DORT) são caracterizados pela ocorrência de diversos sintomas, concomitantes ou não, geralmente nos membros superiores, tais como dor, parestesia, sensação de peso e fadiga, principalmente nos membros e grupos musculares mais utilizados na realização das atividades de trabalho, e frequentemente originam incapacidade laboral temporária ou permanente. Entre os fatores de risco para o surgimento das LER/DORT estão a repetitividade dos movimentos, manutenção de posturas que geram sobrecarga por tempo prolongado, pressão mecânica sobre determinadas partes do corpo e esforço físico intenso, entre outras (Brasil, 2012).

Em relação às condições físicas e materiais, foram identificados como aspectos prejudiciais à saúde dos trabalhadores os altos níveis de ruídos, a exposição a variações de temperatura e a inadequação de instrumentos, como carrinhos de transporte, caixas e tambores de armazenamento de alimentos. Tais fatores também foram apontados como nocivos em outros estudos Monteiro et al. (2014). Segundo Casarotto e Mendes (2003), Green e Anthony (2015) e Jorge et al. (2009), o ruído excessivo é um dos principais fatores de risco em restaurantes universitários. A pesquisa realizada por Green e Anthony (2015) reconheceu a baixa exposição a ruídos superiores ao limite estabelecido pelo Instituto Nacional de Segurança e Saúde Ocupacional (NIOSH), entretanto, de acordo com os autores, essa exposição é suficiente para afetar a audição e para o desenvolvimento posterior de perda auditiva induzida pelo ruído, o que condiz com as condições de saúde dos trabalhadores deste estudo, já que $18 \%$ percebeu problemas ou diminuição da audição.

Verificaram-se discrepâncias existentes entre as tarefas prescritas e a atividade real de trabalho. As prescrições determinadas pelas 
descrições de cargos pouco claras e abrangentes são contrastadas com os ajustes realizados pelo próprio trabalhador para que os objetivos sejam atingidos. Entretanto, tais ajustes implicam em custos que se refletem nos âmbitos da saúde física e psíquica dos trabalhadores, neste caso, se manifestando em forma de sobrecarga de trabalho e conflitos interpessoais.

No que diz respeito às condições do ambiente sociogerencial, notouse que os profissionais relataram intensos conflitos entre a equipe de trabalho e com seus superiores, sendo que os fatores mais relatados pelos participantes foram a dificuldade no relacionamento interpessoal, a ausência de diálogo e cooperação, e a baixa integração entre funcionários novos e antigos. Observa-se que a dimensão afetiva do custo humano neste contexto está ligada ao dispêndio emocional demandado nas interações com os trabalhadores da equipe da cozinha e com a equipe técnica e chefia frente aos diversos conflitos, e, além disso, pode afetar negativamente a saúde dos mesmos (Krumm, 2013; Zanelli, Calzaretta, García, Lipp, \& Chambel, 2010). Por fim, os aspectos problemáticos identificados nos processos e características da atividade foram a distribuição desigual de tarefas na escala e a sobrecarga de atividades, gerada principalmente pela disponibilidade limitada de funcionários aptos para o cumprimento de certas atividades da escala de trabalho. Tais fatores, segundo Guimarães (2006), podem constituir estressores e prejudicar a saúde e o desempenho dos funcionários.

\section{Considerações finais}

Os resultados evidenciados pela análise ergonômica do trabalho empreendida neste estudo sugerem a exposição dos trabalhadores do restaurante universitário a uma série de condições adversas no trabalho, que possivelmente ocasionaram o agravamento de suas condições de saúde. Os fatores de risco ergonômicos e psicossociais relacionados ao trabalho, ou seja, o ambiente físico, a carga de trabalho elevada, e as dificuldades nas relações socioprofissionais podem ser consideradas variáveis que interferem na saúde mental e física do trabalhador.

De acordo com o referencial teórico da Ergonomia da Atividade, cujo objetivo principal é a transformação do ambiente de trabalho, a fim de resultar em maior conforto e prevenção de agravos à saúde dos trabalhadores, é necessário que inicialmente se compreenda as relações estabelecidas entre trabalho e trabalhador. Assim, justificase a importância de conhecer os aspectos relacionados à organização do trabalho, condições de trabalho e às relações socioprofissionais. Portanto, a metodologia utilizada (AET) mostrou-se pertinente para trazer à luz aspectos relevantes na realidade organizacional que 
poderiam constituir riscos ocupacionais para os trabalhadores, oferecendo um instrumental consistente para o planejamento de intervenções em saúde do trabalhador nas organizações.

Sendo assim, este estudo contribuiu para salientar a importância de se analisar e compreender o trabalho como um todo, incluindo as condições físicas, contratuais, os processos e características da atividade e as condições sociogerenciais. Apenas a realização de um diagnóstico organizacional que inclua todos esses componentes do trabalho é capaz de fornecer subsídio para a realização de intervenções no ambiente físico e psicossocial do trabalho, que possam de fato transformar o trabalho visando a promoção de saúde e ao mesmo tempo a produtividade. O diagnóstico realizado respaldou o processo decisório dos gestores da universidade em relação à terceirização das operações do restaurante universitário, bem como auxiliou no processo de realocação dos servidores concursados que tiveram que ser transferidos para outras funções. As atividades do restaurante universitário foram terceirizadas.

Em relação às limitações do estudo, a compreensão e análise do trabalho realizado pela chefia e equipe técnica do restaurante poderiam ter sido inseridas na análise dos dados, a fim garantir uma apreensão mais ampla e acurada do contexto de trabalho estudado. Sugere-se como agenda de pesquisa a realização de diagnósticos por psicólogos organizacionais e do trabalho brasileiros na área da ergonomia, com foco na saúde do trabalhador, em diferentes contextos de trabalho e com a participação de trabalhadores de diversos setores, utilizando a ergonomia da atividade como referencial teórico e metodológico, visando contribuir para transformações no trabalho e melhoria da saúde dos profissionais brasileiros.

\section{Referências}

Abrahão, J., Sznelwar, L., Silvino, A., Sarmet, M., \& Pinho, D. (2009). Introdução à Ergonomia: Da prática à teoria (Cap. 6, pp. 179233). São Paulo, SP: Editora Blucher.

Alencar, M. C. B., Cavalcanti, T. A., \& Montrezor, J. B. (2013). Condições de trabalho em uma cozinha industrial e distúrbios osteomusculares de trabalhadores. Cadernos de Terapia Ocupacional da UFSCar, 21(1), 155-162. doi:10.4322/cto.2013.020

Brasil. (2012). Dor relacionada ao trabalho: Lesões por esforços repetitivos (LER) distúrbios osteomusculares relacionados ao trabalho (Dort). Brasília: Ministério da Saúde. Recuperado de http://bvsms.saude.gov.br/bvs/publicacoes/dor_relacionada_tr abalho_ler_dort.pdf 
Borges, L. O., Costa, M. T., Alves-Filho, A., \& Falcão, J. (2015). Condições de trabalho. In P. F. Bendassoli, \& J. E. BorgesAndrade (Orgs.), Dicionário brasileiro de psicologia do trabalho e das organizações (pp. 230). São Paulo, SP: Casa do Psicólogo.

Braun, V., \& Clarke, V. (2006). Using thematic analysis in psychology. Qualitative Research in Psychology, 3(2), 77-101. doi: 10.1191/1478088706qp063oa

Carvalho, F. M. (2008). Contribuições da Ergonomia para projetos de Unidades de Alimentação. Trabalho apresentado no XIII Encontro Latino Americano de Iniciação Científica e IX Encontro Latino Americano de Pós Graduação, Universidade do Vale do Paraíba, São José dos Campos, SP, Brasil. Recuperado de http://www.inicepg.univap.br/cd/INIC_2009/anais/arquivos/RE _0004_0921_01.pdf

Camarotto, J. A., Simonelli, A. P., \& Rodrigues, D. D. (2013). Ergonomia e trabalho. In A. P. Simonelli \& D. D. Rodrigues (Orgs.), Saúde e trabalho em debate: Velhas questões, novas perspectivas (pp. 33-54). Brasília, DF: Paralelo 15.

Casarotto, R. A., \& Mendes, L. F. (2003). Queixas, doenças ocupacionais e acidentes de trabalho em trabalhadores de cozinhas industriais. Revista Brasileira de Saúde Ocupacional, 28(107/108), 119-126. doi:10.1590/S030376572003000200011

Falzon, P. (Ed.) (2007). Ergonomia. São Paulo, SP: Editora Blucher.

Ferreira, L. L. (2015). Sobre a análise ergonômica do trabalho ou AET. Revista Brasileira de Saúde Ocupacional, 40(131), 8-11. doi:10.1590/0303-7657ED0213115

Ferreira, M. C., \& Mendes, A. M. (2003). Trabalho e risco de adoecimento: o caso dos auditores fiscais da previdência social brasileira. Brasília, DF: Ler, Pensar, Agir.

Gemma, S. F. B., Fuentes-Rojas, M., \& Soares, M. J. B. (2017). Agentes de limpeza terceirizados: Entre o ressentimento e o reconhecimento. Revista Brasileira de Saúde Ocupacional, 42, e4. doi:10.1590/2317-6369000006016

Guèrin, F., Laville, A., Daniellou, F., Duraffourg, J., \& Kerguelen, A. (2001). Compreender o trabalho para transformá-lo: A prática da Ergonomia. São Paulo: Edgard Blücher.

Guimarães, L. A. M. (2006). Fatores psicossociais de risco no trabalho. Trabalho apresentado no Congresso Internacional sobre Saúde Mental no Trabalho, Goiânia, GO, Brasil. Recuperado de http://www.prt18.mpt.gov.br/eventos/2006/saude_mental/anai s/artigos.htm

Green, D. R., \& Anthony, T. R. (2015). Occupational noise exposure of employees at locally-owned restaurants in a college town. 
Journal of Occupational and Environmental Hygiene, 12(7), 489-499. doi:10.1080/15459624.2015.1018517

Haruyama, Y., Matsuzuki, H., Tomita, S., Muto, T., Haratani, T., Muto, S., \& Ito, A. (2014). Burn and cut injuries related to job stress among kitchen workers in Japan. Industrial Health, 52(2), 113-120. doi:10.2486\%2Findhealth.2013-0143

Haukka, E., Leino-Arjas, P., Ojajärvi, A., Takala, E.P., Viikari Juntura, E., \& Riihimäki, H. (2011). Mental stress and psychosocial factors at work in relation to multiple-site musculoskeletal pain: A longitudinal study of kitchen workers. European Journal of Pain, 15(4), 432-438. doi:10.1016/j.ejpain.2010.09.005.

Jorge, A. T., Glina, D. M. R., Isosaki, M., Ribeiro, A. C. Di C. A., Ferreira Junior, M., \& Rocha, L. E. (2009). Distúrbios osteomusculares do trabalho: fatores de risco em trabalhadores de nutrição hospitalar. Revista Brasileira de Medicina do Trabalho, 7, 2-10. Recuperado de http://www.rbmt.org.br/details/140/pt-BR/disturbiososteomusculares-do-trabalho--fatores-de-risco-emtrabalhadores-de-nutricao-hospitalar

Krumm, D. (2013). Estresse, segurança e saúde do empregado. In D. Krumm, Psicologia do Trabalho: Uma introdução à Psicologia Industrial/Organizacional (pp. 277-299). Rio de Janeiro: LTC.

Linhares, J. E., Marcis, J., Tonello, R., Pessa, S. L. R., Adamczuk, G. O. (2016). Demandas e ambiente de trabalho: Um estudo de caso ergonômico em um restaurante universitário do sudoeste do Paraná. Revista Espacios, 37(26), p.14. Recuperado de http://www.revistaespacios.com/a16v37n26/16372614.html

Martinez, M. C., Latorre, M. R. D. O., \& Fischer, F. M. (2017). Estressores afetando a capacidade para 0 trabalho em diferentes grupos etários na Enfermagem: Seguimento de 2 anos. Ciência \& Saúde Coletiva, 22(5), 1589-1600. doi:10.1590/1413-81232017225.09682015

Mendes, A. M. (2008). Trabalho e saúde - O sujeito entre emancipação e servidão. Curitiba, PR: Juruá.

Monteiro, M. A. M., Ramos, C. G. C., Ribeiro, R. C., \& Garcia, M. A. V. T. (2014). Condições de trabalho em restaurantes comerciais de uma instituição pública de ensino. O Mundo da Saúde, São Paulo, 38(3), 306-313. doi:10.15343/01047809.20143803306313

Pizo, C. A., \& Menegon, N. L. (2010). Análise ergonômica do trabalho e o reconhecimento científico do conhecimento gerado. Producão, 20(4), 657-668. doi:10.1590/S010365132010005000058

Silva, M. C., \& Borges, L. O. (2015). Condições de trabalho e clima de segurança dos operários da construção de edificações. Revista 
Psicologia, Organizações e Trabalho, 15(4), 407-418. doi:10.17652/rpot/2015.4.626

Subramanian, S., \& Murugesan, S. (2015). Investigation of workrelated musuloskeletal disorders among male kitchen workers in South India. International Journal of Occupational Safety and Ergonomics, 21(4),

524-531. doi: $10.1080 / 10803548.2015 .1096063$

Tuomi, K., Ilmarinen, J., Jahkola, A., Katajarinne, L., \& Tulkki, A. (2005). Índice de capacidade para o trabalho. São Carlos, SP: EdUFSCar.

Zanelli, J. C., Calzaretta, A. V., García, A. J., Lipp, M. E. N., \& Chambel, M. J. (2010). Trabalho, saúde e construção da qualidade de vida. In J. C. Zanelli (Coord.), Estresse nas organizações de trabalho: Compreensão e intervenção baseadas em evidências (pp. 19-30). Porto Alegre, RS: Artmed.

\section{Endereço para correspondência \\ Marina Greghi Sticca}

Universidade de São Paulo

Faculdade de Filosofia, Ciências e Letras de Ribeirão Preto

Departamento de Psicologia

Av. Bandeirantes, 3900, Monte Alegre, CEP 14040-901, Ribeirão Preto - SP, Brasil

Endereço eletrônico: marinagreghi@hotmail.com

\section{Marina Bernardo Mandarini}

Universidade de São Paulo

Faculdade de Filosofia, Ciências e Letras de Ribeirão Preto

Departamento de Psicologia

Av. Bandeirantes, 3900, Monte Alegre, CEP 14040-901, Ribeirão Preto - SP, Brasil

Endereço eletrônico: marinamandarini@gmail.com

\section{Flavia Helen Moreira da Silva}

Universidade de São Paulo

Faculdade de Filosofia, Ciências e Letras de Ribeirão Preto

Departamento de Psicologia

Av. Bandeirantes, 3900, Monte Alegre, CEP 14040-901, Ribeirão Preto - SP, Brasil

Endereço eletrônico: flavia.helen.silva@gmail.com

Recebido em: 07/02/2019

Reformulado em: 16/08/2019

Aceito em: 16/08/2019

\section{Notas}

* Doutor.

** Mestre.

$* * *$ Mestre com doutorado em andamento.

Este artigo de revista Estudos e Pesquisas em Psicologia é licenciado sob uma Licença Creative Commons Atribuição-Não Comercial 3.0 Não Adaptada. 